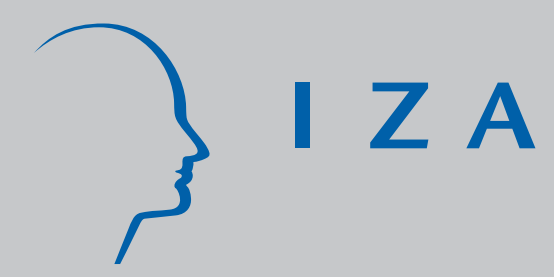

IZADP No. 1510

Inflation Adjustment and Labour Market Structures:

Evidence from a Multi-Country Study

Luca Nunziata

Christopher Bowdler

March 2005 


\title{
Inflation Adjustment and Labour Market Structures: Evidence from a Multi-Country Study
}

\author{
Luca Nunziata \\ Nuffield College, Oxford, \\ University of Milan and IZA Bonn \\ Christopher Bowdler \\ Nuffield College, Oxford

\section{Discussion Paper No. 1510 \\ March 2005}
P.O. Box 7240
53072 Bonn
Germany

Phone: +49-228-3894-0

Fax: +49-228-3894-180

Email: iza@iza.org

\begin{abstract}
Any opinions expressed here are those of the author(s) and not those of the institute. Research disseminated by IZA may include views on policy, but the institute itself takes no institutional policy positions.
\end{abstract}

The Institute for the Study of Labor (IZA) in Bonn is a local and virtual international research center and a place of communication between science, politics and business. IZA is an independent nonprofit company supported by Deutsche Post World Net. The center is associated with the University of Bonn and offers a stimulating research environment through its research networks, research support, and visitors and doctoral programs. IZA engages in (i) original and internationally competitive research in all fields of labor economics, (ii) development of policy concepts, and (iii) dissemination of research results and concepts to the interested public.

IZA Discussion Papers often represent preliminary work and are circulated to encourage discussion. Citation of such a paper should account for its provisional character. A revised version may be available directly from the author. 
IZA Discussion Paper No. 1510

March 2005

\section{ABSTRACT}

\section{Inflation Adjustment and Labour Market Structures: Evidence from a Multi-Country Study}

An empirical analysis of the impact of labour market structures on the response of inflation to macroeconomic shocks is presented. Results based on a 20 country panel show that if labour market coordination is high, the effect on inflation of movements in unemployment, import prices, tax rates and productivity is dampened, both on impact and dynamically. In contrast, monopoly power in labour supply, measured by the percentage unionisation of the workforce, appears to amplify the response of inflation to its reduced form determinants. These findings are attributed to the behaviour of wages following movements in demand- and supply-side conditions.

JEL Classification: E31, J51

Keywords: inflation, input price shocks, labour market coordination, trade union density

Corresponding author:

Luca Nunciata

Nuffield College

Oxford, OX1 1NF

United Kingdom

Email: luca.nunziata@nuffield.ox.ac.uk 


\section{Introduction}

Empirical modelling of the inflation process has a long history in macroeconomics. Studies in this area have typically employed extended Phillips curve models that explain inflation in terms of its own lags (possibly proxying for inflation expectations), the unemployment rate and factors that may shift the aggregate supply curve, for instance productivity growth and import price inflation. Although the demand and cost-side variables that enter a reduced form inflation equation are likely to be similar across countries, the coefficients multiplying these variables differ substantially. Boschen and Weise (2004), for example, document large differences in the impact of oil and commodity price shocks on inflation rates across the OECD, and explain these differences using a measure of political support for low inflation. In this paper we examine the impact on inflation adjustment of two important characteristics of the labour market - the degree of coordination amongst labour organisations and the percentage unionisation of the workforce. These variables may affect the response of inflation to macroeconomic shocks through influencing wage dynamics.

The empirical evidence that we present is based on panel data for 20 OECD countries observed from the 1960s through to the 1990s. The analysis yields two main findings. Firstly, the response of inflation to lagged inflation, unemployment, productivity growth and import price inflation is a decreasing function of the level of labour market coordination. Thus, for a given path for each of these variables, the evolution of inflation will be more stable in countries in which labour market coordination is above the OECD average. Secondly, the effect of import price inflation, productivity growth and indirect tax changes on inflation increases with the unionisation rate, implying that the trajectory of inflation is more volatile the more highly unionised the labour market, all other factors held constant. These findings are generally robust to controlling for further determinants of inflation dynamics, varying the time and cross-sectional dimensions of the panel and adopting alternative methods of estimation.

The remainder of the paper develops these points and is structured as follows. Section 2 expands on the potential links between labour market structures and the parameters determining inflation adjustment. Section 3 sets out the econometric model used to measure the strength of these effects and describes the data. Section 4 reports the empirical results and Section 5 
concludes.

\section{Labour markets and inflation adjustment}

It has often been recognised that labour market structures play a role in determining the response of inflation to macroeconomic shocks. Bruno and Sachs (1985) argue that the relatively mild increase in German inflation following the oil price shocks of the 1970s was in part due to the corporatist structures in which German labour unions participated, as this set of arrangements facilitated a deceleration of wages that in turn restricted inflation pressures. In more recent contributions both Burdekin and Siklos (1999) and Boschen and Weise (2004) note a possible role for labour market structures in accounting for cross-country differences in inflation dynamics.

The extent to which unions coordinate their actions during the wage bargaining process is a potential determinant of the responsiveness of inflation to supply- and demand-side pressures. In highly coordinated labour markets wage negotiations occur close together in time and the level of communication between unions representing different groups of workers is high. This means that unions are more likely to be aware of the macroeconomic consequences of their decisions. ${ }^{1}$ If the union objective function depends on inflation as well as unemployment and the real wage, as in Cukierman and Lippi (1999) for example, unions will have an incentive to moderate wage demands in order to limit the increase in inflation associated with macroeconomic imbalances such as unemployment below the natural rate or an increase in the cost of imports. This incentive will be felt more strongly in coordinated labour markets in which unions are better able to make the connection between wage demands and subsequent price increases. In contrast, when coordination is limited unions may act assuming that their decisions do not

\footnotetext{
${ }^{1}$ Labour market coordination is closely related to the concept of labour market centralisation, the effects of which have been studied by, inter alia, Calmfors and Driffill (1988) and Cukierman and Lippi (1999). Centralisation is the inverse of the number of unions in the market. A high level of centralisation is likely to yield a high level of coordination, since a small number of unions increases the chances of synchronised wage negotiations. However, it should be noted that a market comprising many unions may still be associated with a high level of coordination, e.g. if the government sponsors a forum for wage negotiations. Likewise, a centralised market may still lead to low coordination if unions attempt to 'leapfrog' one another in securing pay deals. Thus, centralisation and coordination are distinct concepts.
} 
affect macroeconomic outcomes, in which case wage moderation will be limited and the upturn in inflation high. Thus, a key hypothesis that we test is that macroeconomic variables such as unemployment and import prices exert smaller effects on inflation in highly coordinated labour markets.

The percentage of workers that are members of a trade union may also affect inflation adjustment. If higher unionisation rates are associated with increased monopoly power in the labour market, workers may be able to extract greater compensation following cost shocks that raise the cost of living, or demand shocks that lead to labour shortages. Consequently the upturn in inflation associated with these shocks will be larger. Hence, this paper also tests for stronger responses of inflation to macroeconomic conditions when unionisation rates are above the OECD average.

The effect of labour market structures on the relationship between inflation and measures of costs and excess demand may take effect through time rather than being confined to a single period. Therefore we also test for a link between labour market institutions and the extent to which inflation depends upon lagged inflation, since this autoregressive parameter influences the shape of the impulse response line for inflation following a shift in one of the its determinants. The extent of the backward-looking component in inflation is often referred to as inflation persistence and is the focus of a large literature in macroeconomics. In recent contributions, Driscoll and Holden (2003a, 2004) argue that inflation persistence is the result of coordination failure in the labour market, and based upon this insight one could conjecture a negative relationship between the autoregressive parameter for inflation and the extent of labour market coordination. Although the results that we present in Section 4 are consistent with this hypothesis, we do not emphasise the finding given that we estimate inflation persistence conditional upon many other variables (see the discussion below), whilst the theoretical literature focuses upon unconditional inflation persistence. The impact of labour market structures on inflation persistence is an important topic for future research. 


\section{$3 \quad$ Econometric methodology}

In order to investigate the determinants of inflation adjustment we use pooled time series data for 20 OECD countries to fit a model in which inflation is explained in terms of lagged inflation and measures of excess demand and input costs. Interactions between these macroeconomic variables and institutional characteristics then account for cross-country and temporal variation in the coefficients of the reduced form inflation equation. Specifically, we estimate models of the form

$$
\text { inf } f_{i t}=\gamma_{0}+\gamma_{1}^{\prime} \mathbf{x}_{1}+\gamma_{2}^{\prime} \mathbf{x}_{2}+\mu_{i}+\lambda_{t}+\varepsilon_{i t}
$$

where $i$ denotes a country ${ }^{2}$ and $t$ a year from the period 1961-95. The term inf is the annual rate of inflation for the consumer price index $(C P I)$ constructed as $\left[\frac{C P I_{i t}-C P I_{i t-1}}{C P I_{i t-1}}\right]$. The vector $\mathbf{x}_{1}$ comprises macroeconomic variables that influence inflation and $\mathbf{x}_{2}$ comprises interactions between the variables in $\mathbf{x}_{1}$ and the two labour market variables, namely coordination and union density (further discussion is provided below). The model allows the regression intercept to vary across countries via the fixed effects $\mu_{i}$, and the time dummies $\lambda_{t}$ control for unobserved influences on inflation that are common across countries, e.g. a reduction in the price-cost markup arising from increased competition as part of the globalisation process. The properties of the error term $\varepsilon_{i t}$ will be addressed in the discussion of the estimation technique at the end of this section.

Macroeconomic variables The variables included in $\mathbf{x}_{1}$ are all measured in decimal form (a reading of $1 \%$ corresponds to .01) and are defined below (data sources are provided in the appendix).

- $i n f_{i t-1}$ is the lagged inflation rate.

- unempit is the deviation of the unemployment rate from its trend level. The trend is calculated separately for each country using the Hodrick-Prescott filter based on a smoothing

\footnotetext{
${ }^{2}$ The countries in the sample are Australia, Austria, Belgium, Canada, Denmark, Finland, France, Germany, Ireland, Italy, Japan, the Netherlands, Norway, New Zealand, Portugal, Spain, Sweden, Switzerland, the UK and the US.
} 
parameter of 400 (the recommended value for annual observations). Detrending of the unemployment series is intended to remove permanent shifts that reflect structural rather than cyclical influences on unemployment. ${ }^{3}$

- import $_{i t}$ is the rate of import price inflation multiplied by the openness of country $i$, the latter being measured as the average ratio of nominal import expenditures to nominal GDP over the period $1961-95$. This adjustment controls for the fact that import price inflation will affect consumer price inflation with a larger coefficient in relatively open economies and therefore deals with a potential source of parameter heterogeneity. ${ }^{4}$

- $\operatorname{prod}_{i t}$ is the rate of productivity growth scaled by one minus average openness (the latter again measured over $1961-95)$. Productivity growth is defined as the percentage change in output per person employed. The adjustment applied controls for the fact that domestic productivity growth will be more important in restricting inflation pressures in relatively closed economies.

- itax $_{i t}$ is the percentage growth rate of the indirect tax wedge, constructed as total indirect taxes minus total subsidies, all divided by private final expenditures (a scaling factor based on openness is not applied because indirect taxes apply to both imported and domestically produced goods).

- $d t a x_{i t}$ is the growth rate of the ratio of direct taxes to households' current receipts scaled by one minus average openness.

The data are available for the period 1961 - 95. A more natural sample period would be 1961 - 98 because 1998 is the last year prior to the introduction of the European single currency. After this date the inflation processes for many countries may have changed due to exchange rates being fixed permanently and control of interest rates being handed to the European Central Bank. Unfortunately we were unable to collect data on the two tax variables for the period 1996 - 98 and therefore the core sample period is $1961-95$. However, in the next section we report a regression for the 1961 - 98 period that uses the variables that are available,

\footnotetext{
${ }^{3}$ It is recognised, however, that statistical filtering has been criticised in some parts of the literature and therefore later in the paper we check the robustness of our results using an unadjusted series for unemployment.

${ }^{4}$ Average openness for 1961 - 95 rather than openness at the annual frequency is used as the scaling factor because the latter may be affected by cyclical effects that are handled by a separate regressor.
} 
and find that the results are very similar to those obtained for the core sample.

Labour market characteristics The labour market variables are defined below. See the appendix for data sources, Nickell et al (2005) and the references therein for further details concerning the construction of the variables, and Nunziata (2004a) for a description of the different series and a discussion of the splicing technique used to ensure comparability of the figures for Germany before and after unification.

- COORD measures the extent to which parties to wage bargaining are able to take account of the macroeconomic consequences of their decisions. This depends on factors such as the level at which negotiations take place (e.g. the national, industry or plant level) and the role of the government in coordinating wage negotiations. The index lies in the range $1-3$, where 3 denotes the highest level of coordination.

- $T U$ is the union membership rate for employees, often referred to as trade union density. The feasible range for this variable is $0-1$.

The vector $\mathbf{x}_{2}$ contains interactions between the macroeconomic variables in $\mathbf{x}_{1}$ and the labour market variables. If the impact on inflation of a macroeconomic variable $x_{a 1}$ depends on, say, labour market coordination, the strength of this effect will be measured by the coefficient multiplying $x_{a 1} \cdot$ coord. In the $\mathbf{x}_{2}$ vector all variables measuring labour market characteristics are defined such that their mean across the panel is zero, i.e. they differ by a constant from the original series. This ensures that the coefficient on each macroeconomic variable can be interpreted as the coefficient of the "average" country, i.e. the country characterised by the sample average value of the labour market characteristic. In the results section a variable preceded by $Z$ indicates that it is in zero mean form.

The macroeconomic variables entering equation (1) are all growth rates, except unemployment which is a deviation from a Hodrick-Prescott trend. Empirical models of inflation often feature error correction terms, defined as the gap between the current price level and a longrun solution for prices (all variables in logs). A typical long-run solution for the price level would be a weighted average of unit labour costs (wages paid per unit of output) and import prices, see for example de Brouwer and Ericsson (1998). In equation (1) terms in wages are deliberately excluded because wage adjustment is the channel through which we expect labour 
market structures to affect the responsiveness of inflation to unemployment, import price shocks, productivity growth and tax shocks. Therefore, in general, it will not be possible to specify a correct long-run solution for prices using the variables in $(1) .{ }^{5}$ Instead, we concentrate on the relationship between growth rates, though in extensions of our main results we experiment with some error correction type terms and find that our conclusions are largely unaltered.

\subsection{The estimation procedure}

Initially we assume that the error process, $\varepsilon$ in equation (1), is heteroscedastic but that individual elements are uncorrelated across both $i$ and $t$. This implies that the model can be estimated by OLS and t-ratios calculated using the heteroscedasticity consistent standard errors due to White (1980). ${ }^{6}$

Before proceeding to the empirical results we discuss three issues relevant to the estimation of macro panel models. Firstly, the second moments of the OLS estimator depend on the order of integration of the variables. The macroeconomic variables are formulated as first differences of price or production variables (except unemp which is a deviation from a Hodrick-Prescott trend) and we therefore hypothesise that each of them is $I(0)$. This is largely confirmed by Augmented Dickey-Fuller (ADF) tests conducted separately for each country and each series: A total of 114 tests performed rejected the unit root hypothesis 99/114 times, with 9/15 of the non-rejections occurring for the unemployment variable (tests were not carried out for Portugal because the data start in 1975, leaving relatively few degrees of freedom). Given that the ADF test often has low power in samples of the size that we are using, we treat unemp as an $I(0)$ variable. ${ }^{7}$ The institutional variables included in $\mathbf{x}_{2}$ are often constant for long periods or change only very slowly, and as such are not amenable to unit root testing. However, as they are both bounded processes they cannot drift without limit and therefore will not introduce spurious non-stationarity to the model.

\footnotetext{
${ }^{5}$ In terms of the underlying econometrics, the levels of prices and costs are normally thought of as I(1) processes that cointegrate to yield an $\mathrm{I}(0)$ error correction term that drives the $\mathrm{I}(0)$ inflation rate. Excluding wages from the analysis implies that a cointegrating vector is unlikely to exist, in which case an error correction model cannot be specified.

${ }^{6}$ Unless otherwise stated, estimation results were obtained using PcGive 10.0, see Doornik and Hendry (2000).

${ }^{7}$ Details of the unit root tests are available on request.
} 
Secondly, Nickell (1981) shows that OLS estimation is inconsistent when applied to models that include fixed effects and a lagged dependent variable. However, the magnitude of the bias is of order $\left(\frac{1}{T}\right)$, where $T$ is the time dimension of the panel. As $T=35$ in this case, any 'Nickell bias' will be extremely limited. This is confirmed in Judson and Owen (1999), who demonstrate by means of Monte Carlo simulations that OLS estimation of the dynamic fixed effects model performs well for $T \geqslant 30$.

Thirdly, the pooled regression model that we estimate is valid only under the assumption that the slope coefficients are homogeneous across countries. In the case of the $\gamma_{1}^{\prime}$ coefficients in (1) an obvious source of heterogeneity is handled by scaling relevant variables according to the openness of each country, as discussed above. The remaining heterogeneity in the $\gamma_{1}^{\prime}$ is the main focus of the analysis, in that we attempt to explain this variation using the vector of labour market institutions (and in robustness checks the set of controls used to explain parameter heterogeneity is extended to include central bank independence, the exchange rate regime and dummy variables for periods of inflation targeting and international wars). Thus, a wide range of controls are used to account for possible cross-country heterogeneity in the $\gamma_{1}^{\prime}$ coefficients.

There remains the possibility of cross-country heterogeneity in $\gamma_{2}^{\prime}$, the coefficients measuring the impact of labour market institutions on the response of inflation to its reduced form determinants. A test of parameter homogeneity such as that proposed by Roy (1957), Zellner (1962) and Baltagi (1995) cannot be carried out because for some countries the coord variable is constant over the sample period, which means that (1) cannot be estimated separately for each country. Instead, we evaluate the extent of parameter heterogeneity through estimating (1) for sub-samples obtained through deleting one country at a time from the panel; if parameter heterogeneity is important the recursively estimated coefficients will appear unstable. As we report in section 4.2 , the estimation results are remarkably stable, suggesting that any violations of the pooling assumptions necessary to estimate $\gamma_{2}^{\prime}$ do not seriously affect the results.

\section{Empirical results}

In Table 1 we present some basic regressions. The sample comprises 644 observations, but 6 of them are accounted for by including impulse dummies. These observations were identified by 
running a simple AR(1) model, including fixed effects and time dummies, and identifying the residuals more than four times larger (in absolute value) than the residual standard deviation. Such larger outliers correspond to special events in the data, for instance a surge in UK inflation following the removal of price controls in 1975, and may exert undue influence on estimated inflation dynamics. ${ }^{8}$

The first column of Table 1 contains the basic determinants of inflation, but does not include interaction terms. Each variable is significant at the $5 \%$ level or better, the error autocorrelation tests do not indicate model mis-specification and the regression standard error, at $1.61 \%$, is roughly one third of the unconditional standard deviation for inflation. The coefficient estimates are reasonable despite the level of aggregation that the model entails. For example given that import price inflation has been scaled by openness, its expected equilibrium impact on inflation is unity, which is within two standard errors of the static coefficient for import, which is $\frac{.39}{1-.56}=.89$.

The coefficient on the productivity term indicates that only one fifth of a productivity improvement is reflected in lower prices in the first year, with the remainder being passed into higher wages or higher profits. It is possible that some attenuation bias affects this coefficient because of measurement errors in the productivity data, e.g. due to changes in average hours worked per person, which have not been taken into account due to a lack of data. The tax coefficients are small, but not implausible. Suppose that the average sales tax over the sample is $10 \%$. A $1 \%$ increase in the variable itax then corresponds to a $0.1 \%$ increase in the sales tax rate, which one might expect to induce a $0.1 \%$ increase in prices, and 0.1 is approximately the value of the static coefficient that multiplies itax. It is more difficult to assign a prior to the value of the dtax coefficient given that it will mainly depend on the elasticity of wages with respect to the direct tax wedge, which is an unknown parameter.

Columns (2) and (3) add interactions between the macroeconomic variables and zero mean versions of coord and $t u$ and in column (4) a restricted specification is reported. ${ }^{9}$ This is obtained from an iterative process in which the least significant term is deleted and the model

\footnotetext{
${ }^{8}$ The observations are: Japan 1974, New Zealand 1985, Portugal 1977, Portugal 1984, Spain 1977, United Kingdom 1975.

${ }^{9}$ Interaction terms based on an index of employment protection were used in some early regressions but turned out to be insignificant. In order to save space we do not report these regressions
} 
re-estimated until all variables are significant at the $5 \%$ level. Coordination in the labour market decreases the responsiveness of inflation to movements in unemployment, import price inflation and productivity. The interaction between unemployment and coord is consistent with the finding in Nunziata (2004b) that the responsiveness of real wages to unemployment is dampened in highly coordinated labour markets. The negatively signed interaction between import price inflation and coordination is consistent with the conclusion of Bruno and Sachs (1985) that corporatist economies were less severely affected by the oil price hikes of the 1970s because they were able to reduce wage growth in order to accommodate adverse economic conditions. The inflation decreasing effect of productivity growth is weaker in highly coordinated labour markets, possibly because firms reward unions for wage moderation during periods of macroeconomic stress through increasing wages by more when productivity growth is high.

The coefficient on lagged inflation is a decreasing function of labour market coordination. This implies that in addition to squeezing the response of inflation to movements in costs and excess demand in the first year, labour market coordination dampens the dynamic response of inflation to such shocks. In sum, for a given pattern of shocks, high levels of labour market coordination appear to smooth the trajectory of inflation.

A relatively high unionisation rate increases the response of inflation to import price and indirect tax movements. One interpretation of this is that monopoly power in labour supply causes wage negotiators to demand greater compensation following increases in the cost of living. A surprising finding is that relatively high levels of unionisation cause each $1 \%$ increase in productivity to reduce inflation by a larger amount. This may reflect the fact that some of the observations for productivity growth are actually negative. If high unionisation rates amplify the increase in inflation following a productivity reversal the coefficient estimate for $\operatorname{prod} \cdot z t u$ will turn out negative, as in column 4. Entering positive and negative productivity observations separately in the model yields a coefficient for $\operatorname{prod}^{-} \cdot z t u$ that takes a larger negative value than that for $\operatorname{prod}^{+} \cdot z t u$, indicating some support for this idea (results are not reported in the table). However, the latter effect is still negatively signed and both terms are insignificant at the $5 \%$ level. One possibility is that measurement errors affect the productivity variable and are correlated with the unionisation rate. Alternatively it may be a chance finding that reflects 
a Type I error in the testing procedure (in some robustness checks reported later this particular term loses significance at the $5 \%$ level).

In column (5) the levels of labour market coordination and union density are added to the regression in order to check that the interaction terms are not simply proxies for the omission of the levels of the labour market variables. The additional variables are insignificant, while the interaction effects are robust. ${ }^{10}$ Finally, in column (6) we extend the time series dimension of the panel to 1998 for all variables except those involving tax terms and find that the main effects of the labour market variables on inflation adjustment are generally robust to using this slightly larger sample.

The quantitative significance of the interaction terms In Table 2 we use the regression results from Table 1, column 4 to assess the quantitative importance of labour market institutions in setting inflation dynamics. The first column lists the effects of each macro variable if both coord and $t u$ are at their sample averages (these are simply the $\gamma_{1}$ coefficients from column 4 of Table 1). In order to obtain the results in the next two columns we set coord and tu equal to their time average values for each country and then calculate the total derivatives for inflation with respect to each macroeconomic variable. The columns headed 'Absolute max' and 'Absolute min' give the maximum and minimum absolute values respectively for the total derivatives, and the countries for which those values occur are given beneath the coefficients.

The maximum and minimum derivatives calculated for each of the explanatory variables differ considerably. In each case the maximum absolute parameter is roughly twice that estimated for the 'average' country, while the minimum absolute parameter is close to zero. If all countries experience a $10 \%$ increase in import prices in a particular year, consumer price inflation in Canada rises by $1.3 \%$ in that year $(10 * 0.55 * 0.24$, where 0.24 measures the openness of the Canadian economy) while consumer price inflation in Japan rises by just $0.04 \%$ over the

\footnotetext{
${ }^{10}$ The insignificance of the levels of labour market coordination and union density is expected given that we estimate a reduced form equation that explains most of the variation in inflation. A simple regression of inflation on coord and $t u$ alone yields strongly significant slope coefficients, suggesting that labour market characteristics matter for inflation, but only through their impact on macroeconomic variables. In a related paper, Bowdler and Nunziata (2004), we provide evidence on the role of labour market characteristics in setting average inflation within macroeconomic regimes.
} 
same period $(10 * 0.04 * 0.10$, where 0.10 measures the openness of the Japanese economy). The difference in these impacts effects will be propagated over time given that the simulated autoregressive parameter for Canada, at 0.61, is approximately half as big again as that for Japan, which is 0.43 .

The model points to interesting differences in the unemployment-inflation tradeoff across countries. Table 2 illustrates the most extreme case: Demand expansions that force down the unemployment rate in Austria, Germany and Japan lead to an increase in inflation that is only one fifth of that observed in Canada and the United States. One explanation for this difference is that unions in the highly coordinated labour markets of Austria, Germany and Japan moderate pay claims during periods of rapid growth and low unemployment, and in return see wage growth reduced by a smaller amount during times of recession and high unemployment.

The cross-country variation in productivity parameters is also quite large. In fact, in the case of Japan the productivity variable actually changes sign, though as the derivative that has been calculated is very close to zero we do not attach great importance to this outcome. The difference between the maximum and minimum values of the indirect tax effect is also very large, though it should be noted that the difference between Sweden (maximum impact effect) and Spain (minimum impact effect) decays over time because the parameter for lagged inflation is smaller for Sweden than for Spain (results not shown in the table).

\subsection{Robustness and sensitivity}

The first robustness test that we perform involves adding to the regressions further interaction terms based on alternative determinants of the speed of inflation adjustment. The extra variables that we consider are as follows:

- $c b i$ is an updated version of Cukierman's (1992) index of central bank independence provided by van Lelyveld (2000).

- $e r$ is the de facto exchange rate regime indicator due to Reinhart and Rogoff (2004). This is based on a scale of $1-5$, where higher values indicate greater exchange rate flexibility.

- inft is a dummy variable set to unity for those years in the sample during which inflation targeting regimes were in effect for more than half of the year, namely Australia $1994-95$, 
Canada 1991 - 95, Finland, 1993 - 95, New Zealand 1990 - 95, Spain 1994 - 95, Sweden 1993 - 95 and United Kingdom 1993 - 95 (these dates are based on those quoted in Bratsiotis et al (2002)).

- oilshock is a dummy variable set to unity during 1973, 1974, 1979 and 1980 for each country. This allows for the possibility that inflation dynamics behave differently during the years of the major oil price hikes, as suggested in Burdekin and Siklos (1999).

- war is a dummy variable set to unity for those years during which a country was heavily involved in an international war. These are as follows: Australia 1964-73, France 1991, United Kingdom 1982 and 1991 and United States 1964 - 73 and 1991. This provides a check on the Burdekin and Siklos (1999) claim that wars lead to changes in inflation dynamics.

The results for these extended regression specifications are presented in Table 3. In the first column a zero mean version of $c b i$ is interacted with each of the macroeconomic variables and these terms are added to the preferred specification (Table 1, column 4). In order to avoid clutter, only those additional regressors that are significant at the $5 \%$ level are reported in the table (full details can be obtained on request). The parameter multiplying lagged inflation decreases with central bank independence. This is consistent with the findings of Boschen and Weise (2004). Crucially from the point of view of this paper, the magnitude and statistical significance of the labour market variables is very robust.

In column (2) we perform the same exercise for the exchange rate regime indicator. One additional term proves significant, and indicates that inflation is more responsive to unemployment under flexible exchange rate regimes. The results in column (3) indicate only a weak effect of inflation targeting regimes on inflation adjustment. This is probably due to the estimation sample ending in 1995, which leaves little time for inflation targeting schemes to take effect (Bratsiotis et al (2002) discuss this point). In both columns the effects of labour market institutions are robust, and the same is true in column (4), which contains interaction terms for oilshock and war.

The final robustness check in this sub-section entails adding error correction type terms to the regressions. Recall that in section 3 we discussed the role of error correction terms in empirical inflation equations. A typical error correction term takes the form $(p-\alpha \cdot u l c-(1-\alpha) i p)$ where 
$p$ is the consumer price index, ulc unit labour costs and $i p$ import prices. This expression can be reformulated as real wages, minus productivity, plus real import prices. As explained previously, we do not condition on wages given that wage adjustment is the channel through which labour market institutions may affect inflation dynamics. However, we can condition on the levels of productivity and real import prices in order to obtain some insight into the impact of error correction type terms on our results. In column (5) of Table 3 levelprod( $(-1)$ is the lagged level of the natural log of productivity multiplied by one minus average openness and realimport $(-1)$ is the lag of the log ratio of import prices to consumer prices multiplied by average openness. ${ }^{11}$

The inclusion of the levels terms actually increases the absolute coefficient values for import and prod relative to Table 1, column (4). In most cases the relationships between labour market institutions and inflation dynamics are preserved, though two terms lose significance at the $5 \%$ level, these being $\operatorname{prod} \cdot z t u$ (recall that we queried the sign of this variable during the discussion at the start of this section) and import ztu. The interactions involving zcoord each remain significant at the $5 \%$ level, though with some reduction in their quantitative importance.

Temporal stability The next robustness check that we perform entails estimating the preferred specification for the periods $1961-79$ and $1980-95$ in order to check the temporal stability of the model. This is important because during the 1970s many countries used price controls in order to limit inflation, and these interventions may be the cause of structural breaks in the regression coefficients. The results are presented in Table 4 (the zero mean variables are re-defined for the sub-samples in order to ensure that they are exact). Each of the coefficients retain their signs from the full sample regression. The effects are often insignificant at the $5 \%$ level, especially during the first half of the sample in which the data are more noisy (the regression standard error is larger in the first column of Table 4 than in the second). However, only in the case of the prod $\cdot$ zcoord interaction is there a substantial loss of significance. Given that some imprecision in the estimates is quite likely when reducing the sample by half, we focus mainly on the behaviour of the point estimates. Bearing this criterion in mind, we note that

\footnotetext{
${ }^{11}$ These variables are not interacted with institutional indicators because such interactions would imply that labour market variables affect the long-run elasticities of consumer prices with respect to import prices and productivity, whereas the focus of this paper is short-run inflation adjustment.
} 
the main examples of instability occur in the case of itax $\cdot z t u$, an effect that is mainly confined to the first half of the sample, and prod $\cdot z t u$ (the term for which the regression coefficient is of unexpected sign) which exerts an effect during only the second half of the sample. Overall, however, the magnitudes of the key interactions terms are quite robust and do not appear to depend on specific periods such as the 1970s.

Cross-sectional stability In Table 5 we present results from an evaluation of the crosssectional stability of the model. This exercise entails deleting one country at a time from the panel, re-estimating the model for each of the 20 sub-samples, and then searching for the maximum and minimum absolute values for each of the interactions presented in Table 1, column 4. These are reported in the second and third columns of the table, along with the corresponding absolute t-ratios and the countries that are excluded in order to give the maxima and minima. The first column summarises the full sample estimates. Overall, the results are encouraging, in that the determinants of inflation adjustment do not depend on any particular country, except the $\operatorname{prod} \cdot$ zcoord term, which generates a t-ratio of 1.62 when Japan is excluded from the sample. This is an isolated case, however, and the Japanese observations do not seem to be the dominant source of cross-sectional variation in the coefficients (the set of countries listed beneath the coefficients is quite varied). The maximum and minimum point estimates are almost always within one standard error of their full sample counterparts, indicating that whilst there are some cross-country differences in the way that labour market institutions affect inflation dynamics, these are not especially important and are unlikely to induce large biases in the estimation of the pooled coefficients.

A more stringent evaluation of cross-sectional stability entails deleting a group of countries rather than one at a time. As the consumer price index in Australia, New Zealand, the United Kingdom and the United States is affected by mortgage interest payments made by households (at least during part of the sample), there is a case for expecting some differences in inflation adjustment in these countries. Thus, a model excluding these four countries was estimated. The results (not reported here but available on request) show that the interaction terms remained significant in most cases, though the unemp zcoord coefficient did fall to 0.03 (t-ratio of 0.35 ). On the other hand, the interaction term $\inf (-1) \cdot z$ coord generated a point estimate of -0.15 
(absolute t-ratio of 6.05), indicating that some of the results are much stronger in the sub-sample.

Alternative estimation methods and variable definitions In Table 6 we report our final set of robustness checks. The first column uses a feasible generalised least squares method to estimate the preferred model, allowing for country specific AR(1) error parameters and country specific heteroscedasticity. ${ }^{12}$ The second column presents the OLS coefficient estimates obtained previously but calculates standard errors that allow for cross-sectional correlation in the residuals (these may arise if, for example, there exists a common shock to European inflation rates that is not accounted for by either the time dummies or the macroeconomic variables). ${ }^{13}$ In both cases the relationship between labour market institutions and inflation dynamics is robust.

The third column replaces unemp, the deviation of the unemployment rate from a $H P(400)$ trend, with the unadjusted unemployment series, simply denoted unemployment, in order to investigate the effects of the detrending method. It appears that the impact of labour market coordination on the response of inflation to unemployment relies on the use of filtered unemployment data, since the interaction term unemployment $\cdot$ zcoord is insignificant in column (4) and the point estimate actually changes sign. Furthermore, there is some weakening of the interaction effects inf $(-1) \cdot z$ coord and prod $\cdot z t u$. It is not surprising that the unadjusted unemployment series leads to some changes in the results given that permanent shifts in the equilibrium unemployment rate surely have occurred in some OECD countries during the period since 1960. Therefore we do not emphasise the importance of the final column of results.

\section{Summary}

This paper has argued that inflation adjustment in OECD countries may depend on labour market structures. In highly coordinated labour markets trade unions are able and willing to restrict the inflationary effects of macroeconomic shocks through their wage-setting decisions. On the other hand, greater monopoly power in labour supply, measured by the percentage

\footnotetext{
${ }^{12}$ Although earlier tests indicated that the average error autocorrelation across countries is zero, the effect may be non-zero for some countries.

${ }^{13}$ The results in columns (1) and (2) were obtained using STATA 8.0. The column (2) results use the 'panel corrected standard errors' command.
} 
unionisation rate of the workforce, may lead to some amplification of the inflationary effects of macroeconomic shocks.

The results generally supported these hypotheses. In particular, the effect on inflation of a $1 \%$ change in unemployment, import prices and productivity was shown to be a decreasing function of an index of labour market coordination, both within the first year of a shock and at longer horizons. In contrast, these responses were found to be increasing in the percentage unionisation of the workforce. The degree of central bank independence, the exchange rate regime and periods of inflation targeting and major international wars also played a role in determining international differences in inflation adjustment, but none of these factors eliminated the important effects arising from labour market structures. These findings were, for the most part, robust to changes in the sample size and the estimation method employed.

\section{Acknowledgements}

We are grateful to Iman van Lelyveld for sending us his data on central bank independence, and to Andrew Glyn for helpful discussions on this topic. 


\section{Appendix: data sources}

inf is constructed from CPI data obtained from the OECD annual national accounts except in the case of Denmark and the Netherlands, for which the source is the International Financial Statistics database maintained by the International Monetary Fund.

unemp is based on unemployment data taken from Layard et al (1991) and is updated using the OECD Employment Outlook 2000. The Portuguese data are from the London School of Economics CEP-OECD database, and the data for Italy are based on the US Bureau of Labor Statistics series, "unemployment rates on US concepts".

import is constructed using import price indices and data on nominal import expenditures and nominal GDP, all taken from the International Financial Statistics database maintained by the International Monetary Fund.

prod is constructed using data for constant price GDP and total employment taken from the OECD national accounts.

itax is constructed using data on total indirect taxes, total subsidies and total private final expenditures, all extracted from the London School of Economics CEP-OECD database.

dtax is constructed using data on total direct taxes and households' current receipts, the source being the London School of Economics CEP-OECD database.

coord is an index from Belot and Van Ours (2000) and is constructed using OECD data on bargaining coordination. Linear interpolation methods are used to obtain annual data for this series.

$t u$ is the ratio of employed union members to total employees. For European countries other than Sweden the source is Ebbinghaus and Visser (2000). For the other countries the sources are Visser (1996) and Huber et al (1997). The latter series are updated by Nunziata (2004a). 


\section{References}

[1] Alogoskoufis, George (1992). "Monetary accommodation, exchange rate regimes and inflation persistence." Economic Journal, 102, 461-480.

[2] Baltagi, Badi (1995). Econometric analysis of panel data. Wiley, 1995.

[3] Belot, Michele and Jan Van Ours (2000). "Does the recent success of some OECD countries in lowering their unemployment rates lie in the clever design of their labour market reforms?" IZA discussion paper 147.

[4] Boschen, John and Charles Weise (2004). "Does the dynamic time consistency model of inflation explain cross-country differences in inflation dynamics?" Journal of International Money and Finance, $23,735-759$.

[5] Bowdler, Christopher and Luca Nunziata (2004). "What determines inflation performance in OECD countries? New evidence from panel data." Mimeo, Nuffield college, University of Oxford.

[6] Bratsiotis, George, Jakob Madsen and Christopher Martin (2002). "Inflation targeting and inflation persistence." Mimeo, Manchester University and Brunel University.

[7] Bruno, Michael and Jeffrey Sachs (1985). Economics of Worldwide Stagflation. Harvard University Press, Cambridge, MA.

[8] Burdekin, Richard and Pierre Siklos (1999). "Exchange rate regimes and shifts in inflation persistence: does nothing else matter?" Journal of Money, Credit and Banking, 31, 235-247.

[9] Calmfors, Lars and John Driffill (1988). "Bargaining structure, corporatism, and macroeconomic performance." Economic Policy, 14-61.

[10] Cukierman, Alex (1992). Central bank strategy, credibility and independence: theory and evidence. The MIT Press, Cambridge MA.

[11] Cukierman, Alex and Francesco Lippi (1999). "Central bank independence, centralization of wage bargaining, inflation and unemployment: Theory and some evidence." European Economic Review, 43, 1395-1434.

[12] de Brouwer, Gordon and Neil Ericsson (1998). "Modelling Inflation in Australia", Journal of Business and Economic Statistics 16, 433-449.

[13] Doornik, Jurgen and David Hendry (2001). "Empirical Econometric Modelling Using 
PcGIVE 10." London: Timberlake Consultants Press.

[14] Driscoll, John and Steinar Holden (2003a). "Coordination, fair treatment and inflation persistence." Working paper, Board of Governors of the Federal Reserve System.

[15] Driscoll, John and Steinar Holden (2003b). "Inflation persistence and relative contracting." American Economic Review 93, 1369-1372.

[16] Driscoll, John and Steinar Holden (2004). "Fairness and inflation persistence." Journal of the European Economic Association 2, 240-251.

[17] Ebbinghaus, Bernhard and Jelle Visser (2000). "Trade unions in western Europe since 1945." Macmillan.

[18] Huber, Evelyne, Charles Ragin and John Stephens (1997). Comparative Welfare States Data Set. Northwestern University and University of North Carolina.

[19] Judson, Ruth and Ann Owen (1999). "Estimating dynamic panel data models: a guide for macroeconomists." Economics Letters 65, 9-15.

[20] Layard, Richard, Stephen Nickell and Richard Jackman (1991). "Unemployment macroeconomic performance and the labour market." Oxford University Press.

[21] Nickell, Stephen (1981). "Biases in dynamic models with fixed effects." Econometrica $49,1417-1426$.

[22] Nickell, Stephen, Luca Nunziata and Wolfgang Ochel (2005). "Unemployment in the OECD since the 1960s. What do we know?" Forthcoming, Economic Journal.

[23] Nunziata, Luca (2004a). "Recent Trends in OECD Labour Markets: Flexibility and Economic Performance." Mimeo, Nuffield college, University of Oxford.

[24] Nunziata, Luca (2004b). "Institutions and wage determination: a multi-country approach." Mimeo, Nuffield college, University of Oxford.

[25] Reinhart, Carmen and Kenneth Rogoff (2004). "The Modern History of Exchange Rate Arrangements: A Reinterpretation." Quarterly Journal of Economics, 119, 1-48.

[26] Roy, Samarenda Nath (1957). Some aspects of multivariate analysis. Wiley, 1957.

[27] van Lelyveld, Iman (2000). "Inflation, Institutions, and Preferences." Ph.D thesis, Faculty of Policy Sciences, University of Nijmegen, Nijmegen.

[28] Visser, Jelle (1996). "Unionisation Trends. The OECD Countries Union Membership 
File." University of Amsterdam, Centre for Research of European Societies and Labour Relations.

[29] White, Halbert (1980). "A heteroskedastic-consistent covariance matrix estimator and direct test for heteroskedasticity." Econometrica 48, 817-838.

[30] Zellner, Arnold (1962). "An efficient method of estimating seemingly unrelated regression and tests for aggregation bias." Journal of the American Statistical Association 57. 


\begin{tabular}{|c|c|c|c|c|c|c|}
\hline Regression & 1 & 2 & 3 & 4 & 5 & 6 \\
\hline $\inf (-1)$ & $0.56(148)$ & $0.52(132)$ & $0.53(14.3)$ & $0.52(12.9)$ & $0.51(12.2)$ & $0.52(16.4)$ \\
\hline whemp & $-0.43(5.70)$ & $-0.42(6.39)$ & $-0.3(5.20)$ & $-0.40(5.51)$ & $-0.40(5.49)$ & $-0.47(6.77)$ \\
\hline import & $0.39(5.54)$ & $0.38(529)$ & $0.33(4.46)$ & $0.33(4.48)$ & $0.33(4.46)$ & $0.34(487)$ \\
\hline prod & $-0.18(2.94)$ & $-0.17(3.02)$ & $-0.14(2.70)$ & $-0.16(322)$ & $0.18(3.66)$ & $-0.17(4.24)$ \\
\hline$k a x$ & $0.05(7.61)$ & $005(7.17)$ & $004(523)$ & $0.04(6.31)$ & $0.04(6.71)$ & \\
\hline dtax & $0.05(2.02)$ & $004(2.13)$ & $005(227)$ & $0.04(2.07)$ & $0.04(2.11)$ & \\
\hline $\begin{array}{l}\text { coord } \\
\text { tw }\end{array}$ & & & & & $\begin{array}{l}-0.01(1.55) \\
0.02(1.21)\end{array}$ & \\
\hline $\inf (-1)^{\star} z \operatorname{coO} d$ & & $-0.08(2.69)$ & $-0.08(2.52)$ & $-009(320)$ & $-0.08(2.62)$ & $-0.10(3.74)$ \\
\hline unemp $p^{*} z$ coord & & $029(2.70)$ & $0.34(257)$ & $0.27(2.59)$ & $0.26(2.45)$ & $0.19(189)$ \\
\hline import'zcoord & & $-0.21(2.30)$ & $-0.24(2.51)$ & $-024(2.60)$ & $-0.22(2.38)$ & $-0.19(1.90)$ \\
\hline prod $z$ CoOrd & & $0.15(1.78)$ & $0.19(2.71)$ & $0.20(2.80)$ & $0.22(3.50)$ & $0.18(306)$ \\
\hline $\operatorname{da} \times^{*} Z \operatorname{coord}$ & & $-0004(0.37)$ & $-0008(0.69)$ & & & \\
\hline ditax $z \operatorname{coom}$ & & $003(125)$ & $001(0.49)$ & & & \\
\hline $\operatorname{mif}(-1)^{*} z$ tw & & & $-0.08(0.72)$ & & & \\
\hline unemp $p^{*} \pi t u$ & & & $-0002(0.87)$ & & & \\
\hline importt $z t w$ & & & $0.58(234)$ & $0.55(2.20)$ & $0.47(1.89)$ & $0.54(198)$ \\
\hline prod*ztw & & & $-0.52(2.65)$ & $-0.54(2.84)$ & $-0.65(2.82)$ & $-0.48(2.70)$ \\
\hline kax $z$ tu & & & $0.12(3.73)$ & $0.10(3.64)$ & $0.10(3.38)$ & \\
\hline dtax $z$ tw & & & $020(1.42)$ & & & \\
\hline Observations & 644 & 644 & 644 & 644 & 644 & 702 \\
\hline Standard error & $1.61 \%$ & $157 \%$ & $155 \%$ & $1.56 \%$ & $1.56 \%$ & $154 \%$ \\
\hline $\mathrm{AR}(1)$ & 0.42 p.68] & -005 [ .96$]$ & $-0.14[0.89]$ & $-0.22[0.83]$ & -0.21 [ .83$]$ & $-0.45[0.65]$ \\
\hline $\mathrm{AR}(2)$ & $-0.40[0.69]$ & -0.35 [. .73$]$ & $-0.28[0.78]$ & $-0.09[0.93]$ & $0.08[0.94]$ & -0.34 D.74] \\
\hline \multicolumn{7}{|c|}{$\begin{array}{l}\text { OLS regression estim ates for an unbalanced panel of } 20 \text { countries observed for the period } 1961-65 \\
\text { (1961-98 in colum (6)). Al models indude a constant, fixed effeds, time dum mies and six im pulse } \\
\text { dumm ies described in the text. Coefficient estim ates reported, with absolute t-ratios based on } \\
\text { heteroscedasticity consistent standard errors in parentheses. AR(1) and } A R(2) \text { are statistics for error } \\
\text { autocomelation up to orders one and two respectively, p-values in parentheses. }\end{array}$} \\
\hline
\end{tabular}

\begin{tabular}{|c|c|c|c|}
\hline Variable & Coefficient & Absolutem max & Absolute min \\
\hline $\inf (-1)$ & 0.52 & $\begin{array}{c}0.61 \\
\text { Canam, us }\end{array}$ & $\begin{array}{c}0.43 \\
\text { Austria, Gemmany, Jaan }\end{array}$ \\
\hline whemp & -0.40 & $\begin{array}{c}-0.69 \\
\text { Canat, US }\end{array}$ & $\begin{array}{c}-0.14 \\
\text { Austria, Gemmany, Jaan }\end{array}$ \\
\hline import & 0.33 & $\begin{array}{c}0.55 \\
\text { Canada }\end{array}$ & $\begin{array}{l}0.04 \\
\text { Japan }\end{array}$ \\
\hline prod & -0.16 & $\begin{array}{l}-0.34 \\
\text { Canada }\end{array}$ & $\begin{array}{l}0.08 \\
\text { Japan }\end{array}$ \\
\hline $\operatorname{kax}$ & 0.04 & $\begin{array}{c}0.08 \\
\text { Sweden }\end{array}$ & $\begin{array}{l}0.01 \\
\text { Spain }\end{array}$ \\
\hline $\operatorname{ctax}$ & 0.05 & - & - \\
\hline \multicolumn{4}{|c|}{$\begin{array}{l}\text { The coefficients listed in the first column are taken from Table 1, column } 4 . \\
\text { Absolute max gives the largest absolute value for each coefficient. Absolute } \\
\text { min gives the smallest absolute value. Courtries listed are those for } \\
\text { which the maxima and minima ocour. }\end{array}$} \\
\hline
\end{tabular}




\begin{tabular}{|c|c|c|c|c|c|}
\hline Regression & 1 & 2 & 3 & 4 & 5 \\
\hline $\inf (-1)$ & $0.4(135)$ & $0.52(13.7)$ & $0.52(13.0)$ & $0.49(14.2)$ & $0.47(12.3)$ \\
\hline whemp & $-0.41(6.39)$ & $-0.40(5.66)$ & $-0.41(494)$ & $-0.40(5.21)$ & $-0.37(5.54)$ \\
\hline import & $0.32(4.32)$ & $0.34(5.23)$ & $0.33(4.43)$ & $0.46(6.93)$ & $0.37(500)$ \\
\hline prod & $-0.16(306)$ & $-0.15(284)$ & $-0.17(329)$ & $-0.17(3.56)$ & $-0.23(4.22)$ \\
\hline $\operatorname{kax}$ & $0.04(5.23)$ & $0.04(6.11)$ & $0.04(6.08)$ & $005(5.46)$ & $004(824)$ \\
\hline ditax & $0.04(1.86)$ & $0.04(1.99)$ & $0.04(1.88)$ & $003(225)$ & $004(2.15)$ \\
\hline $\inf (-1)^{*} z \operatorname{coord}$ & $-0.11(3.16)$ & $-0.10(321)$ & $-009(299)$ & $-009(4.26)$ & $-0.08(2.49)$ \\
\hline unemp zcoord & $0.26(2.80)$ & $0.26(3.83)$ & $0.25(2.30)$ & $028(259)$ & $0.23(223)$ \\
\hline import $z$ coord & $-0.23(2.36)$ & $-0.25(2.64)$ & $-025(2.62)$ & $-0.28(2.59)$ & $-0.19(2.07)$ \\
\hline $900^{*} z C O O W^{\prime}$ & $0.20(2.93)$ & $0.20(3.21)$ & $0.21(2.94)$ & $0.19(2.50)$ & $0.13(3.10)$ \\
\hline import* ztw & $0.62(2.67)$ & $0.60(2.60)$ & $0.53(2.11)$ & $0.85(3.33)$ & $0.33(1.32)$ \\
\hline$p r o d^{*} \mathrm{zt} u$ & $-0.52(2.30)$ & $-0.50(2.77)$ & $-0.59(2.70)$ & $-0.54(2.95)$ & $-0.36(1.66)$ \\
\hline kax $z$ tw & $0.12(4.62)$ & $0.09(3.13)$ & $0.10(3.26)$ & $0.11(432)$ & $008(306)$ \\
\hline $\inf (-1)^{*} z c b i$ & $-0.31(2.70)$ & & & & \\
\hline unemp ${ }^{*}$ zer & & $-0.18(5.15)$ & & & \\
\hline kax $x^{*}$ inft & & & $-0.10(189)$ & & \\
\hline import* oilshock & & & & $-0.49(3.87)$ & \\
\hline $\min (-1)^{*} w a r$ & & & & $-0.16(3.24)$ & \\
\hline kevelpod (-1) & & & & & $-0.04(4.07)$ \\
\hline realimoont -1 ) & & & & & $0.16(6.81)$ \\
\hline Observations & 644 & 644 & 644 & 644 & 644 \\
\hline Standard error & $1.55 \%$ & $156 \%$ & $1.56 \%$ & $1.52 \%$ & $1.50 \%$ \\
\hline $\mathrm{AR}(1)$ & 0.03 p.97] & $-005[096]$ & -0.22 p 83$]$ & -0.46 p.65] & 0.67 [ 50$]$ \\
\hline $\operatorname{R} R(2)$ & $-0.17[0.87]$ & $002[0.98]$ & -0.13 p 90$]$ & -0.04 p.97] & $0.56 \quad[.51]$ \\
\hline
\end{tabular}

OLS regression estim ates for an unbalanced panel of 20 countries observed for the period 1961-65. See Table 1 for further notes.

\begin{tabular}{|c|c|c|}
\hline Regression & 1: $1961-79$ & 2: $1980-1995$ \\
\hline $\operatorname{inf(-1)}$ & $0.42(7.65)$ & $0.53(10.5)$ \\
\hline whemp & $-0.74(5.78)$ & $0.28(3.48)$ \\
\hline import & $0.36(2.62)$ & $0.28(4.50)$ \\
\hline prod & $-0.25(2.31)$ & $-0.24(3.36)$ \\
\hline$k a x$ & $003(2.20)$ & $0.07(5.33)$ \\
\hline ctax & $003(1.4)$ & $004(1.00)$ \\
\hline $\inf (-1)^{*} z \operatorname{coor} d$ & $-0.13(1.92)$ & $0.08(1.73)$ \\
\hline unemp*zcoord & $024(1.03)$ & $029(3.14)$ \\
\hline import'zcoom & $-0.28(1.93)$ & $0.15(154)$ \\
\hline$p r o d^{*} z c 00 r d$ & $008(0.68)$ & $0.10(1.37)$ \\
\hline import*ztw & $0.83(1.76)$ & $0.43(2.47)$ \\
\hline$p r o d^{*}$ Ztw & $-0.08(0.23)$ & $-0.77(191)$ \\
\hline kax $z t w$ & $026(3.22)$ & $004(0.51)$ \\
\hline Observations & 325 & 319 \\
\hline Standard error & $1.65 \%$ & $1.42 \%$ \\
\hline$A R(1)$ & 021 p.84] & $-021[083]$ \\
\hline $\mathrm{AR}(2)$ & $-0.49[0.62]$ & $-1.18[024]$ \\
\hline
\end{tabular}

OLS regression estimates for an unbalanced panel of 20 countries. See Table for further notes. 


\begin{tabular}{|c|c|c|c|}
\hline \multicolumn{4}{|c|}{ Table 5: Variations in the ooefficients when dropping countries } \\
\hline Interadion term & Full sample & Absolute max & Absolute $\mathrm{m}$ in \\
\hline $\inf (-1)+2000 \mathrm{~d}$ & $-009(3.20)$ & $\begin{array}{c}-0.11(4.54) \\
U K\end{array}$ & $\begin{array}{c}-0.08(2.78) \\
\text { Finland }\end{array}$ \\
\hline whemp $z$ coord & $0.27(2.59)$ & $\begin{array}{c}0.34(3.13) \\
\text { Germany }\end{array}$ & $\begin{array}{c}021(201) \\
\text { US }\end{array}$ \\
\hline import" $z$ coord & $-024(2.60)$ & $\begin{array}{c}-0.28(2.98) \\
\text { Japan }\end{array}$ & $\begin{array}{c}-0.17(2.16) \\
\text { thaly }\end{array}$ \\
\hline$p r o d^{*} \mathrm{ZCOOH}$ & $0.20(2.80)$ & $\begin{array}{c}0.23(322) \\
\text { reland }\end{array}$ & $\begin{array}{c}009(1.62) \\
\text { Japan }\end{array}$ \\
\hline import*ztw & $0.56(220)$ & $\begin{array}{c}0.68(2.84) \\
\text { France }\end{array}$ & $\begin{array}{l}0.30 \text { (199) } \\
\text { Netherlands }\end{array}$ \\
\hline$p \infty O Q^{*} \pi t w$ & $-0.54(2.84)$ & $\begin{array}{c}-0.62(3.12) \\
\text { Portugal }\end{array}$ & $\begin{array}{c}-0.42(2.4) \\
\text { Japan }\end{array}$ \\
\hline$k a x^{*} z t w$ & $0.10(3.64)$ & $\begin{array}{c}0.12(2.48) \\
\text { Spain } \\
\end{array}$ & $\begin{array}{l}008 \text { (3.47) } \\
\text { Switzenland }\end{array}$ \\
\hline \multicolumn{4}{|c|}{$\begin{array}{l}\text { The first colum n gives coefficient estim ates based on Table } 1 \text {, } \\
\text { colum n } 4 \text { (absolute t-ratios in parentheses). Absolute m ax gives the } \\
\text { largest absolute value for the coefficient obtained from } 20 \text { sub- } \\
\text { sample regressions based on deleting one country at a time. } \\
\text { Absolute min gives the sm allest absolute values. The countries for } \\
\text { which the maxima and minima occur are given beneath the } \\
\text { coefficient estimates. }\end{array}$} \\
\hline
\end{tabular}

\begin{tabular}{|c|c|c|c|}
\hline Regression & 1 & 2 & 3 \\
\hline Estim ation method & FGLS & OLSIPCSE & OLS \\
\hline $\inf (-1)$ & $0.53(20.82)$ & $0.52(15.43)$ & $0.52(136)$ \\
\hline whemp & $-0.40(6.44)$ & $-0.40(6.18)$ & \\
\hline impont & $031(701)$ & $0.33(600)$ & $0.33(4.43)$ \\
\hline prod & $-0.19(4.33)$ & $-0.16(3.13)$ & $-0.22(3.77)$ \\
\hline $\operatorname{dax}$ & $004(4.15)$ & $0.04(401)$ & $0.04(627)$ \\
\hline dtax & $002(224)$ & $0.04(3.14)$ & $0.05(228)$ \\
\hline $\inf (-1)^{*} z \operatorname{coor}$ & $-0.09(3.27)$ & $-0.09(2.56)$ & $-005(1.55)$ \\
\hline whemp* zcoord & $024(281)$ & $0.27(2.72)$ & \\
\hline import zcoord & $-0.23(3.56)$ & $-0.24(2.49)$ & $-029(3.02)$ \\
\hline$p r o d^{*} z \operatorname{coord}$ & $0.18(334)$ & $0.20(2.99)$ & $0.26(3.15)$ \\
\hline impont* $z t w$ & $0.44(2.44)$ & $0.56(328)$ & $0.59(2.46)$ \\
\hline proo* ztu & $-0.50(2.23)$ & $-0.54(2.40)$ & $-0.32(1.30)$ \\
\hline kax $z$ th & $0.11(205)$ & $0.10(185)$ & $0.12(4.67)$ \\
\hline unemployment & & & $-0.15(3.75)$ \\
\hline whemployment zcoord & & & $-0.007(0.27)$ \\
\hline Observations & 644 & 644 & 644 \\
\hline Standard error & $157 \%$ & $156 \%$ & $1.59 \%$ \\
\hline $\mathrm{AR}(1)$ & $\cdot$ & $\cdot$ & $004[097]$ \\
\hline $\mathrm{AR}(2)$ & - & - & $-0.45[.641$ \\
\hline
\end{tabular}

See notes to Table 1. Additional notes: FGLS denotes feasible generalised least squares estim ation, allowing for country specific AR(1) errors and heterosoedasticity. OLSIPCSE is ordinary least squares with panel correded standard errors accounting for cross-country correlations in the error process. 